\title{
Transient global amnesia in four brothers
}

\author{
RICHARD N CORSTON, RICHARD B GODWIN-AUSTEN \\ From the Regional Department of Neurology, Derbyshire Royal Infirmary, Derby, UK
}

SUMMARY The case histories are described of four brothers who suffered attacks of transient global amnesia. The coincidence of this disorder in four siblings suggests that the causative factors in transient global amnesia may have a familial basis and that its incidence is more common than generally realised.

In 1956 Bender $^{1}$ described patients with a "simple episode of confusion and amnesia". Subsequently, in 1958 and 1964 Fisher and Adams ${ }^{2} 3$ reported patients with similar brief episodes of memory loss and used the term transient global amnesia. Since the first descriptions of this syndrome there have been numerous reports of similar cases such that in 1978 Rollinson ${ }^{4}$ was able to review 213 cases which had been reported in the literature. To our knowledge, however, there have been no reports of several members of the same family being affected. We therefore report the case histories of four brothers who suffered attacks of transient global amnesia. Two of the patients were seen and examined by us but two had died previously and details of their medical histories were obtained from medical records.

\section{Case reports}

Case No 1 WJ was a 63-year-old man who had experienced three brief episodes of amnesia. The first occurred in the morning after he had taken a shower. During the attack he dug up his lawn but was subsequently unable to remember doing this. He was unable to recognise anyone but his wife and son. He was amnesic for a period of about 18 hours. His second attack occurred about a year later, again after taking a shower. During this attack he stood and stared out of the window and kept asking where he was and what he was supposed to be doing. A third attack occurred after he had returned to work following his lunch break. He was found wandering around asking people where he was and what he was doing. During this attack he complained of feeling dizzy.

Address for reprint requests: Dr RN Corston, Department of Neurology, Derbyshire Royal Infirmary, London Road, Derby DEI 2QY, UK.

Received 20 October 1980 and in revised form 6 January 1981 Accepted 31 March 1981
He was sedated and put to bed and the next morning he had recovered although he was unable to remember events after lunch of the previous day. When interviewed he explained that three of his six brothers had had similar attacks although none of his five sisters had been affected. On examination he was found to have an arcus senilis and a bradycardia of 48 beats per minute. His full blood count, ESR, blood glucose, urea and electrolytes and liver function tests were all normal as were his EEG, skull radiograph and CT scan. His ECG showed a sinus bradycardia and frequent ventricular extrasystoles.

Case No 2 Ho $\mathrm{J}$ was a 71-year-old man who had suffered two brief episodes of amnesia six and nine years previously. The first attack had started whilst he was in the garden. He suddenly stopped his gardening and went into the house. He initially ignored his wife when she spoke to him but in subsequent conversation said that he was unable to remember having been in the garden and half-an-hour later he had recovered. His second attack again occurred whilst he was gardening. He went into the house and was agitated and confused, asking his wife what he had just been doing. He was perplexed by the presence of a dog in the house since he could not remember having one as a pet. Again, he recovered within about half-an-hour. When examined, no abnormalities were found and his skull radiograph, ECG, EEG and CT scan were all normal.

Case No $3 \mathrm{Ha} \mathrm{J}$ had died suddenly, at the age of 81 years, after a bladder neck resection for persistent urinary problems. WJ said that his brother had suffered two attacks of confusion and memory loss which had each lasted about 18 hours. Both had occurred within the last seven years of his life. In the first attack he awoke one morning and was unable to remember where he was or what he should have been doing that day. He remained confused throughout the rest of the day. The next attack occurred whilst he was sunbathing in the garden. He was suddenly unable to remember the thread of a conversation and denied the fact that he was due to go on holiday 
the following week. Again the amnesia had resolved by the next day. From his medical notes it was discovered that he was hypertensive (BP 180/100 $\mathrm{mmHg}$ ) in 1952 when he was 55-years-old. At this time he complained of chest pains but his ECG was normal. In 1967 he was again seen because of chest pain and he was noted to have an arcus senilis. His ECG showed inverted T waves in leads AVL and in the lateral chest leads and he was diagnosed as having angina. In November 1977, when admitted for his first operation, his ECG showed first degree heart block with occasional Wenckebach phenomenon and widespread ST segment and $\mathrm{T}$ wave abnormalities indicating cardiac ischaemia. At this time he was taking digoxin and sustained release glyceryl trinitrate.

Case No $4 \mathrm{JJ}$ had died in 1972 at the age of 77 years after an episode of acute chronic bronchitis and right heart failure. He was said by WJ to have had three attacks of confusion and amnesia in the last two years of his life. Each attack lasted about 24 hours and each had started whilst he was working in the garden. Examination of his medical records showed that he had been diagnosed as having diabetes mellitus in 1971. His blood glucose level was $9.6 \mathrm{mmol} / \mathrm{l}$. He was obese and was treated with a 1000 calorie diet. Prior to his death in 1972 his ECG had shown frequent ventricular extrasystoles.

\section{Discussion}

The descriptions of the attacks of amnesia obtained from two of the brothers were typical of transient global amnesia. They occurred in elderly men of stable psychiatric background who gave no history of alcohol abuse, epilepsy or migraine. ${ }^{5}$ During the attacks they did not lose personal identity but were unable to register memory traces for current events. There was evidence of retrograde amnesia in that one patient was unable to remember that he had a pet dog and the other was unable to recognise people other than his wife and son. Both patients had insight into their memory deficiency being agitated and repeatedly asking questions about their whereabouts and about what they had been doing. The patients were left with a memory gap for the period of the attack. Although the descriptions of the attacks experienced by the other brothers were less detailed they were said to have suffered more than one attack of memory loss and confusion lasting up to a day which were thought to have been attacks of transient global amnesia.

Multiple attacks are now well recognised and may be associated with a permanent memory impairment, ${ }^{6}$ whilst single attacks may lead to a permanent deficit of verbal long-term memory. ${ }^{?}$ Formal neurophysiological testing was not undertaken in our patients but none complained of a permanent memory impairment nor was there any report of residual impairment of memory performance.

Various factors have beẹn deșcribed as precipi- tating transient global amnesia and they include taking a shower ${ }^{8} 9$ and physcial exertion including gardening. ${ }^{9}$ Both these activities were relevant in our cases; the first patient having two attacks following a morning shower and the second and fourth patients having their attacks whilst working in the garden.

There is evidence that bilateral temporal lobe dysfunction is required to cause recent memory defects $\mathbf{1 0}$ and most authors favour a transient vascular insufficiency as the cause of this dysfunction. This would seem to be a factor in our cases since various abnormalities, which have been associated with both transient global amnesia and cerebrovascular disease, were present, namely hypertension, diabetes mellitus and cardiac disease. ${ }^{6}$

That four brothers were affected may in part be explained by the fact that the patients were members of a large family, there being 12 siblings in all. A further consideration, however, is the possibility that transient global amnesia is more common than is generally realised. Certainly only one of the brothers initially sought medical advice about his episodes of amnesia and it may be that many people who suffer such attacks do not consider it necessary to consult a doctor. But the occurrence of attacks in several siblings seems more likely to reflect the fact that the known risk factors (hypertension, diabetes mellitus and cardiac disease) can have a familial component. We conclude that these risk factors summated in this family to cause transient global attacks in four of 12 siblings.

We wish to thank Dr HL Matthews for referring the original case.

\section{References}

${ }^{1}$ Bender MB. Syndrome of isolated episode of confusion with amnesia. J Hillside Hosp 1956;5:212-5.

${ }^{2}$ Fisher CM, Adams RD. Transient global amnesia. Trans Am Neurol Assoc 1958;83:143-5.

${ }^{3}$ Fisher CM, Adams RD. Transient global amnesia. Acta Neurol Scand 1964;40:Suppl 9.

${ }^{4}$ Rollinson RD. Transient global amnesia-a review of 213 cases from the literature. Aust NZ J Med 1978; 8(5): 547-9.

${ }^{5}$ Croft PB, Heathfield KWG, Swash M. Differential diagnosis of transient global amnesia. $\mathrm{Br} \mathrm{Med} J$ 1973;4:593-6.

${ }^{6}$ Mathew NT, Meyer JS. Pathogenesis and natural history of transient global amnesia. Stroke 1974;5: 303-11.

7 Mazzucchi G, Moretti P, Caffarra P, Parma M. Neuropsychological functions in the follow-up of transient global amnesia. Brain 1980;103:161-78.

${ }^{8}$ Martin E. Transient global amnesia. A report of eleven cases including five cases at the seaside. Ir $J$ 
Med Sci 1970;3:331-5.

- Fogelholm R, Kivalo E, Bergstrom L. The transient global amnesia syndrome. An analysis of 35 cases. Eur Neurol 1975;13:72-84.
${ }^{10}$ De Jong RN. The hippocampus and its role in memory. Clinical manifestations and theoretical considerations. J Neurol Sci 1973;19:73-93. 